\title{
Heme stimulates platelet mitochondrial oxidant production via the activation of toll-like receptor 4 signaling to mediate targeted granule secretion
}

Gowtham K. Annarapu1, Deirdre Nolfi-Donegann, ${ }^{1,2}$, Michael Reynolds ${ }^{1}$, Yinna Wang ${ }^{1}$, Lauren Kohut $^{3}$, Brian Zuckerbraun ${ }^{3}$, and Sruti Shiva ${ }^{1,4, *}$

${ }^{1}$ Pittsburgh Heart, Lung, Blood, Vascular Medicine Institute, University of Pittsburgh School of Medicine, Pittsburgh, PA, USA, 15261

${ }^{2}$ Department of Pediatrics, Division of Hematology/Oncology, Children's Hospital of Pittsburgh, Pittsburgh, PA, USA, 15224

${ }^{3}$ Department of Surgery, University of Pittsburgh School of Medicine

${ }^{4}$ Department of Pharmacology \& Chemical Biology, University of Pittsburgh, Pittsburgh, PA, 15261, USA

${ }^{*}$ Corresponding:

Sruti Shiva, PhD

E1220 Thomas E. Starzl Biomedical Science Tower

200 Lothrop Street, Pittsburgh, PA 15213

Phone 412-383-5854

Fax 412-648-5980

E-mail address: sss43@pitt.edu

WORD COUNT

Abstract $=249$

Introduction + Methods + Results + Discussion $=3535$

NUMBER OF FIGURES $=5$

NUMBER OF REFERENCES $=81$

\section{Key points:}

1. Heme induces platelet mtROS production by inhibiting complex-V activity via TLR4 signaling.

2. Heme stimulated platelet granule secretion is regulated by mtROS. 


\begin{abstract}
Hemolysis is a pathological component of many diseases and is associated with thrombosis and vascular dysfunction. Hemolytic products, including cell-free hemoglobin and free heme directly activate platelets. However, the effect of hemolysis on platelet degranulation, a central process in not only thrombosis, but also inflammatory and mitogenic signaling, remains less clear. Our group showed that hemoglobin-induced platelet activation involved the production of mitochondrial reactive oxygen species (mtROS). However, the molecular mechanism by which extracellular hemolysis induces platelet mtROS production, and whether the mtROS regulate platelet degranulation remains unknown. Here, we demonstrate using isolated human platelets that cell free heme is a more potent agonist for platelet activation than hemoglobin, and stimulates the release of a specific set of molecules from the a-granule of platelets, including the glycoprotein thrombospondin-1 (TSP-1). We uncover the mechanism of heme-mediated platelet mtROS production which is dependent on the activation of platelet TLR4 signaling and leads to the downstream phosphorylation of complex-V by the serine kinase Akt. Notably, inhibition of platelet TLR4 or Akt, or scavenging mtROS prevents heme-induced granule release in vitro. Further, heme-dependent granule release is significantly attenuated in vivo in mice lacking TLR4 or those treated with the mtROS scavenger MitoTEMPO. These data elucidate a novel mechanism of TLR4-mediated mitochondrial regulation, establish the mechanistic link between hemolysis and platelet degranulation, and begin to define the heme and mtROS-dependent platelet secretome. These data have implications for hemolysis-induced thrombo-inflammatory signaling and for the consideration of platelet mitochondria as a therapeutic target in hemolytic disorders.
\end{abstract}




\section{Introduction}

Intravascular hemolysis occurs in a number of pathologies ranging from genetic hemoglobinopathies $^{1-3}$ to more acute conditions such as sepsis ${ }^{4}$, pre-eclampsia ${ }^{5,6}$, parasitic infection $^{7,8}$, or in patients after cardiac surgery 9,10 . It is well established that patients with chronic hemolysis, such as in sickle cell disease, are at significantly greater risk for thrombotic complications ${ }^{11,12}$ as well as endothelial dysfunction ${ }^{13,14}$ and chronic vasculopathy ${ }^{15-17}$ which lead to morbidities such as stroke ${ }^{18,19}$ and pulmonary hypertension $(\mathrm{PH})^{20-24}$. However, the mechanisms that link hemolysis, thrombosis, and vasculopathy have not fully been elucidated. Platelets, when activated, are central mediators of thrombosis ${ }^{25-27}$, sentinels of inflammatory signaling 27,28 , and can also propagate vascular responses through the synthesis and release of vasoactive molecules from alpha and dense granules ${ }^{29-31}$. Notably, cell-free hemoglobin $(\mathrm{Hb})$ or free heme released via hemolysis stimulates platelet thrombotic activation ${ }^{32-36}$ and promotes inflammatory signaling 37,38 . At a mechanistic level, these effects have been linked to $\mathrm{Hb}$ dependent modulation of platelet mitochondrial function. Specifically, $\mathrm{Hb}$ inhibits complex $\mathrm{V}$ of the platelet mitochondrial electron transport chain, leading to an increase in mitochondrial reactive oxygen species (mtROS) production, which stimulates platelet activation ${ }^{32}$. Consistent with this mechanism, specific scavengers of mtROS attenuate hemolysis-induced platelet activation $^{32}$ and inflammatory signaling ${ }^{39}$ ex vivo and thrombosis in murine models ${ }^{40}$. Despite the recognition that $\mathrm{Hb}$-induced $\mathrm{mtROS}$ regulates platelet activation and inflammatory signaling, the mechanisms by which hemoglobin or heme released via hemolysis stimulates mtROS production within the platelet is unknown.

Platelet degranulation, while associated with platelet activation, is a tightly regulated process. Although it is estimated that platelet granules contain over three hundred diverse molecules ${ }^{41,42}$, specific patterns of granule contents are released in response to differential platelet agonists ${ }^{31,43-}$ 45. Thrombospondin-1 (TSP-1) a multifunctional glycoprotein that is stored in and secreted from platelet $\alpha$-granules regulates thrombosis ${ }^{46-48}$ as well as inflammatory 49,50 and vascular signaling ${ }^{50,51}$. For example, once secreted, TSP-1 interacts with cell adhesive receptors and integrins to potentiate platelet activation and stabilize platelet aggregation ${ }^{47,52,53}$. Through its selective interaction with CD36 or CD47 on macrophages, other leukocytes, and endothelial cells, TSP-1 can stimulate the inflammatory response through the potentiation of NFkB ${ }^{54}$ and 
TGF- $\beta$ signaling $49,55,56$ and enhancement of leukocyte migration ${ }^{49,57}$. Thrombospondin-1 also inhibits endothelial nitric oxide signaling and enhances matricellular remodeling to propagate vascular remodeling ${ }^{58,59}$. Notably, plasma and platelet TSP-1 levels are significantly increased in conditions with components of hemolysis such as sickle cell disease ${ }^{60,61}$ and sepsis ${ }^{62,63}$ respectively, and genetic inhibition of TSP-1 signaling attenuates vasculopathy in murine models of sickle cell disease ${ }^{64}$ and prevents inflammation and morbidity in a murine model of cecal ligation and puncture induced sepsis ${ }^{65}$. While these studies highlight the role of platelet-derived TSP-1 as a mediator of thrombo-inflammation and vasculopathy, it is unknown whether hemolysis-derived products stimulate TSP1 release, what other granule molecules are released by platelets upon encountering heme, and whether heme-dependent degranulation is regulated by platelet mtROS production.

In this study, we test whether heme and $\mathrm{Hb}$ released via hemolysis stimulate platelet granule release and determined the role of $\mathrm{mtROS}$ in this process. We demonstrate that cell free heme is a more potent stimulator of platelet mtROS production and TSP-1 release than $\mathrm{Hb}$, and that mtROS production is required for the heme-dependent release of TSP-1 and other granule molecules. Further, we demonstrate that mechanistically heme-induced mtROS production requires the activation of platelet TLR4 signaling culminating in the activation of the serine/threonine kinase Akt, which phosphorylates complex $\mathrm{V}$ to inhibit its activity, leading to mtROS generation. These data have implications for the regulation of hemolysis induced thrombotic and vascular signaling, as well as for platelet mitochondria as a therapeutic target in hemolytic disease.

\section{Materials and Methods}

All Chemicals were purchased from Sigma-Aldrich (St. Louis, MO) and antibodies from BD Biosciences (San Jose, CA) unless otherwise noted.

\section{Human blood collection and platelet isolation}

Venous blood was collected from human participants by standard venipuncture after written informed consent was obtained and in accordance with study \#19030018 (approved by the Institutional Review Board of the University of Pittsburgh). 
Platelet rich plasma (PRP) was separated from whole blood collected in acid-citrate dextrose (ACD) Solution-A anticoagulant by centrifugation at 500 rpm for 20 minutes. Platelets were then pelleted in the presence of $\mathrm{PGl}_{2}(1 \mu \mathrm{g} / \mathrm{mL})$ by centrifuging the PRP at 1500xg for 10 minutes. These platelets were washed with erythrocyte lysis buffer containing $\mathrm{PGI}_{2}$ to remove any residual erythrocytes and resuspended in modified Tyrode's buffer (20 mM HEPES, $128 \mathrm{mM} \mathrm{NaCl}, 12$ $\mathrm{mM}$ sodium bicarbonate, $0.4 \mathrm{mM}$ sodium phosphate monobasic, $5 \mathrm{mM}$ dextrose, $1 \mathrm{mM} \mathrm{MgCl}$, $2.8 \mathrm{mM} \mathrm{KCl}, \mathrm{pH}$ 7.4). The platelet count was determined by Hemavet® 950 .

\section{Murine Studies}

TLR4-flox and global TLR4 knockout mice (TLR4 ${ }^{-/}$) were used in accordance with approval from the University of Pittsburgh Institutional Animal Care and Use Committee. Male mice 10-12 weeks in age (24-27g) were administered cell free heme (110 mg/kg) or saline (vehicle) by tail vein injection. Some groups of mice were pre-treated with MitoTEMPO $(300 \mu \mathrm{M})$ administered in the drinking water for 72 hours. Platelet mtROS (assessed via mitoSOX as described below) and cell free plasma concentrations of TSP-1, interleukin-1 beta (IL-1 $\beta$ ), and platelet derived growth factor-B (PDGF-B) were measured 20 min after heme administration.

\section{Measurement of Platelet activation}

Platelet activation was measured in washed platelets by staining with anti-CD41a-PE, antiCD62P (P-selectin)-APC and PAC1 binding antibody-FITC (to bind activated GPIIb/Illa), and then quantification of these markers and CD41a (as a marker of platelets) by flow cytometry (LSR-Fortessa; Becton Dickinson).

In all experiments, washed platelets $\left(2.0-2.5 \times 10^{6} / \mathrm{mL}\right)$ were incubated with heme for 30 minutes prior to measurement of activation. In some experiments, platelets were pre-treated with TLR4 neutralizing antibody $(5 \mu \mathrm{g} / \mathrm{mL}), 2 \mu \mathrm{M}$ of BX795 (TBK1 inhibitor), $100 \mathrm{nM}$ of $\mathrm{N}-[1-[2-(4-$ Morpholinyl) ethyl]-1H-benzimidazol-2-yl]-3-nitrobenzamide (IRAK1/4 inhibitor), 5 nM of (5Z)-7Oxozeaenol (TAK1 inhibitor), and/or 10 $\mu \mathrm{M}$ of MitoTEMPO (mtROS scavenger).

\section{Measurement of mtROS}

Treated washed platelets were pelleted at 1500xg for $5 \mathrm{~min}$, resuspended in HBSS and incubated with $10 \mu \mathrm{M}$ of MitoSOX ${ }^{\mathrm{TM}}$ Red for $5 \mathrm{~min}$, after which fluorescent intensity (510/580 
$\mathrm{nm}$ ) was measured kinetically as previously described ${ }^{32}$. During the pretreatment of platelets with ARQ092 DMSO was used as vehicle control.

\section{Measurement of Thrombospondin-1 (TSP-1) release from platelets}

TSP1 levels were measured using the Human Thrombospondin-1 DuoSet ELISA kit (R\&D systems; DY3074) in the supernatant surrounding treated platelets. During the pretreatment of platelets with ARQ092 DMSO was used as vehicle control.

\section{Dot blot assay}

Conditioned supernatant collected from treated washed platelets was blotted (30 $\mu \mathrm{L})$ on to the $0.4 \mu \mathrm{m}$ nitrocellulose membrane using Bio-Dot Apparatus. The membrane was blocked with blocking buffer for 30 min at room temperature and followed by incubation with primary antibody overnight at $4^{\circ} \mathrm{C}$ (all primary antibodies used for dot blot were purchased form , R\&D systems; anti-Cathepsin A, AF1049; anti-Angiostatin, AF226; anti-CD40L, AF617; anti-Kininogen, AF1569; anti-PAI-1, AF1786; anti-Thrombospondin-1, AF3074; AF795; anti-CXCL7, AF393; anti-IL-1 $\beta$, AF201; anti-PDGF-B, AF220; anti-TGF- $\beta$, AF246; anti-FGF basic, AF233) and IRDye® $800 \mathrm{CW}$ Donkey anti-Goat IgG secondary antibody for 40min at room temperature. The blots were imaged using a LI-COR imaging system and analyzed using Image Studio software.

\section{Mitochondrial Complex V activity assay}

The enzymatic activity of complex $\mathrm{V}$ was measured by spectrophotometrically by kinetic assay as previously described ${ }^{32}$.

\section{Immunoprecipitation of Complex V}

Treated platelets were lysed with RIPA lysis buffer including Halt protease and phosphatase inhibitor cocktail. The beta subunit of complex $\mathrm{V}$ and proteins bound to it were immunoprecipitated using an antibody to the beta subunit of ATP synthase (Millipore, MAB3494) in accordance with the Pierce ${ }^{\mathrm{TM}}$ Co-Immunoprecipitation Kit (Cat.No:26149). Immunoprecipitated samples were subjected to western blot by standard procedure using antipAKT (S473; Cell Signaling, 4060S) and anti-ATP synthase beta subunit antibodies. The blots were imaged using a LI-COR imaging system and analyzed using Image Studio software. 


\section{Statistics}

Unpaired parametric t-tests were used to compare individual group samples and ANOVA along with Tukey post-hoc test were used to make multiple comparisons. Statistical analyses were performed using GraphPad Prism 9 software. P-values $<0.05$ were considered significant. Data are presented as mean \pm standard error of the mean (SEM) unless otherwise specified.

\section{Results}

\section{Heme is a more potent platelet agonist than $\mathrm{Hb}$}

To determine whether heme stimulates platelet activation as potently as $\mathrm{Hb}$, isolated washed human platelets were incubated with heme $(0-20 \mu \mathrm{M})$ or $\mathrm{Hb}(0-40 \mu \mathrm{M})$ and platelet activation was measured. Platelets treated with heme or $\mathrm{Hb}$ both showed a concentration dependent increase in surface P-selectin levels and PAC-1 antibody binding (as a measure of activated GPIlb/Illa), indicative of platelet activation (Figure 1A-B). However, heme treatment stimulated a greater level of surface P-selectin and active GPIIb/llla at every concentration measured (70.9 $\pm 4.03 \%$ P-selectin; $68.14 \pm 2.76 \%$ PAC-1 binding at $2.5 \mu \mathrm{M})$ compared to $\mathrm{Hb}(7.59 \pm 0.40 \%$ P-selectin; $10.41 \pm 2.24 \%$ PAC-1 binding at $2.5 \mu \mathrm{M})$ (Figure 1A-B). These results indicate that heme and $\mathrm{Hb}$ both activate platelets, but heme is a more potent agonist than $\mathrm{Hb}$ for platelet activation. To investigate the role of heme in modulating platelet function beyond activation, we measured the release of TSP-1 from a-granules of heme or $\mathrm{Hb}$ treated platelets, as a marker of platelet granule secretion. We observed significantly greater levels of TSP-1 release in heme stimulated platelets compared to those stimulated with $\mathrm{Hb}$ (Figure 1C), similar to the effect on platelet activation.

Since the platelet granule secretome is agonist specific, we next measured the level of release of a panel of nine common platelet granule molecules in response to heme stimulation. We found that heme induced the release of seven of the granule factors measured (CXCL7, FGF basic, TGF $\beta$, IL-1 $\beta$, PDGF-B, angiostatin, kininogen), while it did not stimulate the release of CD40L and PAI-1 (Figure 1D). These data demonstrate that heme stimulates the release of a specific pattern of granule molecules.

\section{Heme- induced mtROS production stimulates platelet granule release}


We previously showed that $\mathrm{Hb}$ inhibits platelet mitochondrial complex $\mathrm{V}$ activity, which increases mitochondrial inner membrane potential to promote mtROS production, an effect that was associated with platelet activation ${ }^{32}$. To test whether heme similarly modulates platelet mitochondrial function, we treated platelets with heme and measured complex $\mathrm{V}$ activity and mtROS production. Heme treatment significantly decreased platelet mitochondrial complex $\mathrm{V}$ activity (Figure 2A), and concomitantly increased mtROS production (Figure 2B).

To determine whether mtROS production was required for platelet granule release, we measured the levels of release of the eight granule factors identified to be stimulated by heme (TSP1, CXCL7, FGF basic, TGF $\beta$, IL-1 3 , PDGF-B, angiostatin, kininogen) from heme treated platelets in the presence and absence of MitoTEMPO $(10 \mu \mathrm{M})$, a mtROS scavenger. Treatment of platelets with MitoTEMPO significantly decreased heme-induced mtROS levels (Figure 2B) and also significantly attenuated heme-induced release of TSP1, CXCL7, FGF basic, IL-1ß, PDGF-B, angiostatin (Figure 2C-D).

\section{Heme inhibits mitochondrial complex V and induces mtROS in a TLR4 dependent manner}

To determine the mechanism by which extracellular heme mediates intra-platelet signaling, we tested whether a platelet surface receptor was required for heme-mediated platelet granule secretion, focusing on TSP-1 as a marker of heme induced granule release. Since TLR4 is known to mediate heme-dependent responses in other cell types ${ }^{66,67}$, we blocked platelet TLR4 with TLR4 neutralizing antibody $(5 \mu \mathrm{g} / \mathrm{mL})$ and measured complex $\mathrm{V}$ activity and mtROS production in platelets after treatment with heme $(2.5 \mu \mathrm{M})$. Blocking platelet TLR4 attenuated heme-dependent complex $\mathrm{V}$ inhibition (Figure 3A) and significantly decreased heme-induced mtROS production (Figure 3B). Consistent with heme induced TSP-1 secretion being dependent on mtROS production, the presence of TLR4 neutralizing antibody also significantly decreased heme-induced TSP-1 secretion (Figure $3 \mathrm{C}$ ).

Given that blocking platelet surface TLR4 resulted in decreased heme-induced platelet mtROS production by improving complex $\mathrm{V}$ activity and attenuated TSP-1 secretion from heme treated platelets, we sought to determine how TLR4 downstream signaling inhibits complex V activity. We used pharmacological inhibitors to inhibit key downstream kinases in the TLR4 pathway. We blocked signaling associated with the TLR4 adaptor protein MyD88 with inhibitors of kinases 
downstream of MyD88 - IRAK1/4 and TAK1. Additionally, we used inhibitors of TBK1 kinase to test the role of MyD88-independent signaling. Inhibition of TBK1, IRAK1/4 or TAK1 individually significantly attenuated heme-dependent complex $\mathrm{V}$ inhibition (Figure 3A). Similarly, mtROS production in heme-treated platelets was significantly decreased in the presence of the inhibitors of TBK1, IRAK1/4 or TAK1. (Figure 3B). Consistent with the requirement for complex $V$ inhibition and mtROS production to induce TSP-1 release by heme, inhibitors of downstream TLR4 signaling also significantly attenuated TSP-1 release from the heme-treated platelets (Figure 3C). Collectively, these data suggest that heme-dependent TLR4 activation inhibits mitochondrial complex $\mathrm{V}$ and induces mtROS production through MyD88 dependent and independent pathways.

\section{Heme mediated TLR4 signaling promotes AKT phosphorylation to inhibit complex V activity.}

Akt is a serine/threonine-specific protein kinase that can be activated downstream of TLR4 and is known to bind to and phosphorylate a number of mitochondrial proteins, including the $\alpha$ and $\beta$ subunits of complex $\mathrm{V}$, to regulate their function ${ }^{68,69}$. To determine whether heme-induced TLR4 activation requires AKT activation to inhibit complex $\mathrm{V}$ activity, we tested whether AKT binds to complex $\mathrm{V}$ and examined the phosphorylation status of AKT in heme treated platelets. Immunoprecipitation of the beta-subunit of complex $\mathrm{V}$ from heme treated platelets showed that significant levels of Akt were associated with complex V, and measurement of pAKT(S473) showed significant activation of the kinase (Figure 4A). When phosphorylation of AKT was assessed in heme treated platelets pre-treated with blockers of TLR4 signaling (TBK1, IRAK1/4 or TAK1 inhibitors), lower levels of pAKT(S473) bound to complex V were measured (Figure 4A). These data demonstrate that heme-mediated activation of TLR4 stimulates downstream AKT phosphorylation and binding to complex $\mathrm{V}$.

To determine whether heme-induced activation of AKT regulates complex $V$ activity, we treated platelets with heme in the presence and absence of ARC0092, a small molecule that prevents phosphorylation of $\mathrm{AKT}$ at $\mathrm{S} 473^{70}$, and measured complex $\mathrm{V}$ activity. While heme treatment inhibited complex $\mathrm{V}$ activity, this effect was significantly attenuated when AKT phosphorylation was blocked (Figure 4B). Collectively, these data demonstrate that heme-induced TLR4 
activation stimulates the downstream activation of AKT, which binds to complex $\mathrm{V}$ and inhibits its activity.

Given that heme induced mtROS production is essential for TSP-1 release from platelets, and complex $\mathrm{V}$ inhibition (which leads to mtROS production) is dependent on AKT phosphorylation, we tested whether blocking AKT activation decreases heme-induced mtROS production and TSP-1 release. We pretreated platelets with ARC0092, incubated them with heme and measured platelet mtROS production and TSP-1 release. As expected, heme increased both platelet mtROS production and TSP-1 release. However, both these effects were significantly decreased upon blocking AKT phosphorylation (Figure 4C-D).

To determine whether the heme-induced pathway elucidated ex vivo was relevant in a physiological setting in vivo, TLR4 ${ }^{-/}$mice and corresponding control mice (TLR4 flox) were administered cell free heme $(110 \mathrm{mg} / \mathrm{kg})$ to mimic hemolysis and platelet $\mathrm{mtROS}$ was measured. While heme induced platelet mtROS production in control mice, this effect was significantly attenuated in TLR4 ${ }^{-/}$mice (Figure 5A). Measurement of plasma levels of TSP-1, PDGF-B, and $\mathrm{IL}-1 \beta$ showed that heme-induced release of these factors was also significantly attenuated in $\mathrm{TLR}^{-/-}$mice. Consistent with the dependence of mtROS on TLR4 signaling, treatment with MitoTEMPO attenuated heme-induced granule secretion in control mice but had no effect in TLR4 $^{-/-}$mice (Figure 5B).

\section{Discussion}

In this study we demonstrate that while heme and hemoglobin both stimulate platelet activation and TSP-1 release, heme is a more potent platelet agonist than Hb. Mechanistically, we show that heme-mediated TSP-1 release relies on the production of platelet mtROS generation. Further, we elucidate the mechanism by which heme stimulates mtROS production, and find that mtROS production is dependent on heme-mediated activation of TLR4 signaling, culminating in the Akt-dependent phosphorylation and inhibition of complex $\mathrm{V}$ activity. This pathway has implications for not only understanding the pathogenesis of hemolysis-induced thrombotic and inflammatory diseases, but also for the development of potential therapeutics for these conditions. 
Prior studies have independently reported that heme ${ }^{35,36}$ and $\mathrm{Hb}^{32-34}$ stimulate platelet activation, however their potency in the context of platelet agonism has previously not been compared. We show here that heme is a more potent mediator of both platelet activation and TSP-1 release than $\mathrm{Hb}$. It is unclear what factors underlie this increased potency of heme. Heme and $\mathrm{Hb}$ are biochemically distinct species and heme can selectively bind to multiple receptors and transcription factors $35,67,71,72$. Thus, it is likely that heme is either a stronger activator of TLR4 or stimulates multiple signaling pathways that concomitantly contribute to platelet activation and/or TSP-1 secretion. While prior studies demonstrate heme-induced activation of TLR4 ${ }^{67,71}$, it remains unclear whether heme activates TLR4 through traditional ligand binding, and whether $\mathrm{Hb}$ acts similarly. However, consistent with the potential of heme activating concomitant pathways of platelet agonism, Bourne and colleagues showed that heme-mediated activation of C-type-lectin-like-receptor-2 (CLEC-2) contributes to platelet activation ${ }^{35}$. Notably, CLEC-2 activation was observed with higher concentrations of heme $(6.25 \mu \mathrm{M})^{35}$ than used in our study $(2.5 \mu \mathrm{M})$. Given the biphasic effect of heme observed by both groups, in which maximal platelet agonism is observed at $\sim 5-6 \mu \mathrm{M}$ heme, it is possible that while both pathways contribute to hememediated platelet agonism, the contribution of these pathways potentially shifts with increasing concentrations of heme. Further study is required to delineate the contribution of each pathway, their potential cross-talk, and whether stimulation of multiple pathways makes heme a more efficient platelet agonist than $\mathrm{Hb}$.

Though heme-mediated platelet activation is well documented ${ }^{35,36}$, heme-induced platelet granule release has not been extensively studied. It is estimated that platelet granules store over three hundred molecules, including mitogens, chemokines, and thrombotic regulators, which are released in discreet patterns dependent on the specific stimulus ${ }^{31,43-45}$. This study begins to define the heme-dependent platelet secretome by showing that heme induces the release of TSP-1, PDGF-B, IL-1 $\beta$, FGF basic, angiostatin and CXCL7. Importantly, we also identified molecules that are not released in response to heme such as CD40L and PAI-1. Identification of the heme specific platelet secretome may provide a critical link between hemolysis and pathogenic vascular signaling. For example, platelet derived TSP-1 can promote both thrombosis and vascular pathogenesis through its interaction with CD36 on circulating cells and CD47 in endothelial cells ${ }^{47,73-75}$. In severe sepsis patients, plasma TSP-1 levels have been found to be significantly elevated ${ }^{63}$, and recent murine studies of sepsis models show that 
independent of pathogen load, free heme promotes thrombosis ${ }^{76}$. Thus, it is interesting to speculate that heme-induced platelet TSP-1 release potentially drives pathogenic thrombosis in sepsis. Similarly, in sickle cell disease, platelet TSP-1 has been implicated in the pathogenesis of pulmonary hypertension ${ }^{77}$, which is a major cause of morbidity in these patients and is also associated with hemolysis ${ }^{60}$. Notably, plasma TSP-1 levels are significantly elevated in patients with sickle cell disease in steady state 60,78 . In patients who are in vaso-occlusive crisis, which is associated with even higher rates of hemolysis than in steady state, TSP-1 levels associate with lower rates of hemolysis ${ }^{60}$. This is likely consistent with the biphasic curve (Figure 1) for hemedependent TSP-1 release that we demonstrate in this study.

While prior studies have demonstrated that heme induces ROS production in the platelet, this study is the first to demonstrate the mitochondrion as a significant source of heme-induced ROS and to define the mechanism by which heme induces mtROS. Our data demonstrate that heme inhibits mitochondrial complex $\mathrm{V}$ to induce mtROS production, and that this inhibition of complex $\mathrm{V}$ requires heme-mediated activation of platelet TLR4 signaling which ultimately results in Akt activation and association with complex V. Our data are consistent with accumulating reports demonstrating that phosphorylated Akt can translocate and accumulate in the mitochondria, and specifically that Akt can phosphorylate mitochondrial complexes, including the $\beta$-subunit of complex- $\mathrm{V}^{68,69}$. Our data are not entirely consistent with other reports of Akt-dependent complex $\mathrm{V}$ phosphorylation which show that this association leads to activation of the complex $\mathrm{V}$ rather than the inhibition shown in this study. However, inhibitory and activating phosphorylation sites have been identified on complex $\mathrm{V} \beta$-subunit. Thus, it is possible that separate stimuli propagate Akt-dependent phosphorylation of different sites. Further study identifying the heme-dependent phosphorylation site is required for comparison with other stimuli.

The data presented in this study demonstrate that mtROS regulate heme-dependent granule release. While a growing number of reports have established the association between mtROS production and platelet activation in multiple pathologies ${ }^{79-81}$, the specific role of mtROS in regulating platelet function, particularly granule secretion in response to specific agonists, is less clear. Notably, a recent study demonstrates that agonists such as thrombin receptor activator peptide-6 (TRAP-6) activates platelets in a mtROS independent manner, and while scavenging 
mtROS does not affect TRAP-6 dependent platelet activation, it significantly attenuates platelet aggregation $^{80}$. These data are consistent with mtROS regulation of platelet granule secretion independent of regulation of platelet activation. However, further study is required to dissect mtROS regulation of platelet activation versus granule secretion, as well as the molecular mechanisms by which mtROS cause granule release. However, our in vivo data suggest that mtROS scavenging (or TLR4 inhibition to prevent mtROS production) is a potentially viable option in preventing heme-induced platelet dysfunction.

In conclusion, this study demonstrates the mechanism by which extracellular heme signals through platelet TLR4 to induce platelet mtROS production. Further, we demonstrate that hemeinduced mtROS stimulates platelet granule secretion. The data begin to define the hemeinduced platelet secretome and its regulation by mtROS. Overall, these studies advance the

understanding of the mechanisms that link hemolysis to platelet dysfunction. While further study of the secretome is required to determine whether heme-induced secreted products are responsible for hemolysis-associated inflammation and vasculopathy, the data herein demonstrate a central role for the mitochondrion in heme-dependent platelet dysfunction and suggest this organelle as a potential therapeutic target in hemolytic conditions.

\section{Acknowledgments}

This work was supported by NIH grants HL133003-01A1 (to SS) and 1 R01 HL130268-03 (to SS and BZ) and The Hemophilia Center of Western Pennsylvania (to SS).

\section{Authorship Contributions}

GA, DND, MR, YW, LK, BZ and SS designed the study and performed the research. LK and BZ performed murine experiments and collected the data.GA, DND, MR and SS analyzed the data. GA and SS wrote the manuscript.

\section{Conflict of Interest Disclosures}

The authors declare no competing financial interests. 


\section{References}

1. Piel FB, Steinberg MH, Rees DC. Sickle Cell Disease. N Engl J Med. 2017;376(16):1561-1573.

2. Hill A, DeZern AE, Kinoshita T, Brodsky RA. Paroxysmal nocturnal haemoglobinuria. Nat Rev Dis Primers. 2017;3:17028.

3. Fibach E, Rachmilewitz EA. Pathophysiology and treatment of patients with beta-thalassemia an update. F1000Res. 2017;6:2156.

4. Effenberger-Neidnicht K, Hartmann M. Mechanisms of Hemolysis During Sepsis. Inflammation. 2018;41(5):1569-1581.

5. Burwick RM, Rincon M, Beeraka SS, Gupta M, Feinberg BB. Evaluation of Hemolysis as a Severe Feature of Preeclampsia. Hypertension. 2018;72(2):460-465.

6. Ciantar E, Walker JJ. Pre-eclampsia, severe pre-eclampsia and hemolysis, elevated liver enzymes and low platelets syndrome: what is new? Womens Health (Lond). 2011;7(5):555-569.

7. Orf K, Cunnington AJ. Infection-related hemolysis and susceptibility to Gram-negative bacterial co-infection. Front Microbiol. 2015;6:666.

8. Narurkar R, Mamorska-Dyga A, Nelson JC, Liu D. Autoimmune hemolytic anemia associated with babesiosis. Biomark Res. 2017;5:14.

9. Heilmann C, Geisen U, Benk C, et al. Haemolysis in patients with ventricular assist devices: major differences between systems. Eur J Cardiothorac Surg. 2009;36(3):580-584.

10. Vercaemst L. Hemolysis in cardiac surgery patients undergoing cardiopulmonary bypass: a review in search of a treatment algorithm. J Extra Corpor Technol. 2008;40(4):257-267.

11. Ataga KI. Hypercoagulability and thrombotic complications in hemolytic anemias. Haematologica. 2009;94(11):1481-1484.

12. Cappellini MD. Coagulation in the pathophysiology of hemolytic anemias. Hematology Am Soc Hematol Educ Program. 2007:74-78.

13. Rother RP, Bell L, Hillmen P, Gladwin MT. The clinical sequelae of intravascular hemolysis and extracellular plasma hemoglobin: a novel mechanism of human disease. JAMA. 2005;293(13):16531662.

14. Minneci PC, Deans KJ, Zhi H, et al. Hemolysis-associated endothelial dysfunction mediated by accelerated NO inactivation by decompartmentalized oxyhemoglobin. J Clin Invest. 2005;115(12):34093417.

15. Morris CR. Mechanisms of vasculopathy in sickle cell disease and thalassemia. Hematology Am Soc Hematol Educ Program. 2008:177-185.

16. Kato GJ, Hebbel RP, Steinberg MH, Gladwin MT. Vasculopathy in sickle cell disease: Biology, pathophysiology, genetics, translational medicine, and new research directions. Am J Hematol. 2009;84(9):618-625.

17. Kato GJ, Steinberg MH, Gladwin MT. Intravascular hemolysis and the pathophysiology of sickle cell disease. J Clin Invest. 2017;127(3):750-760.

18. Saeed O, Jakobleff WA, Forest SJ, et al. Hemolysis and Nonhemorrhagic Stroke During Venoarterial Extracorporeal Membrane Oxygenation. Ann Thorac Surg. 2019;108(3):756-763.

19. Dubert M, Elion J, Tolo A, et al. Degree of anemia, indirect markers of hemolysis, and vascular complications of sickle cell disease in Africa. Blood. 2017;130(20):2215-2223.

20. Wahl S, Vichinsky E. Pulmonary hypertension in hemolytic anemias. F1000 Med Rep. 2010;2. 
21. Machado RF, Gladwin MT. Pulmonary hypertension in hemolytic disorders: pulmonary vascular disease: the global perspective. Chest. 2010;137(6 Suppl):30S-38S.

22. Rafikova O, Williams ER, McBride ML, et al. Hemolysis-induced Lung Vascular Leakage Contributes to the Development of Pulmonary Hypertension. Am J Respir Cell Mol Biol. 2018;59(3):334345.

23. Haw A, Palevsky HI. Pulmonary hypertension in chronic hemolytic anemias: Pathophysiology and treatment. Respir Med. 2018;137:191-200.

24. Morris CR, Kato GJ, Poljakovic M, et al. Dysregulated arginine metabolism, hemolysis-associated pulmonary hypertension, and mortality in sickle cell disease. JAMA. 2005;294(1):81-90.

25. Koupenova M, Kehrel BE, Corkrey HA, Freedman JE. Thrombosis and platelets: an update. Eur Heart J. 2017;38(11):785-791.

26. Gurbel PA, Jeong YH, Navarese EP, Tantry US. Platelet-Mediated Thrombosis: From Bench to Bedside. Circ Res. 2016;118(9):1380-1391.

27. Koupenova M, Clancy L, Corkrey HA, Freedman JE. Circulating Platelets as Mediators of Immunity, Inflammation, and Thrombosis. Circ Res. 2018;122(2):337-351.

28. Rolfes V, Ribeiro LS, Hawwari I, et al. Platelets Fuel the Inflammasome Activation of Innate Immune Cells. Cell Rep. 2020;31(6):107615.

29. Becker RC, Sexton T, Smyth SS. Translational Implications of Platelets as Vascular First Responders. Circ Res. 2018;122(3):506-522.

30. Shi G, Morrell CN. Platelets as initiators and mediators of inflammation at the vessel wall. Thromb Res. 2011;127(5):387-390.

31. Golebiewska EM, Poole AW. Platelet secretion: From haemostasis to wound healing and beyond. Blood Rev. 2015;29(3):153-162.

32. Cardenes N, Corey C, Geary L, et al. Platelet bioenergetic screen in sickle cell patients reveals mitochondrial complex $\mathrm{V}$ inhibition, which contributes to platelet activation. Blood.

2014;123(18):2864-2872.

33. Annarapu GK, Singhal R, Gupta A, et al. HbS Binding to GP1balpha Activates Platelets in Sickle Cell Disease. PLoS One. 2016;11(12):e0167899.

34. Singhal R, Annarapu GK, Pandey A, et al. Hemoglobin interaction with GP1balpha induces platelet activation and apoptosis: a novel mechanism associated with intravascular hemolysis.

Haematologica. 2015;100(12):1526-1533.

35. Bourne JH, Colicchia M, Di Y, et al. Heme induces human and mouse platelet activation through C-type-lectin-like receptor-2. Haematologica. 2020.

36. NaveenKumar SK, SharathBabu BN, Hemshekhar M, Kemparaju K, Girish KS, Mugesh G. The Role of Reactive Oxygen Species and Ferroptosis in Heme-Mediated Activation of Human Platelets. ACS Chem Biol. 2018;13(8):1996-2002.

37. Conran N, De Paula EV. Thromboinflammatory mechanisms in sickle cell disease - challenging the hemostatic balance. Haematologica. 2020;105(10):2380-2390.

38. Belcher JD, Nath KA, Vercellotti GM. Vasculotoxic and Proinflammatory Effects of Plasma Heme: Cell Signaling and Cytoprotective Responses. ISRN Oxidative Med. 2013;2013.

39. Vats R, Brzoska T, Bennewitz MF, et al. Platelet Extracellular Vesicles Drive Inflammasome-IL1 beta-Dependent Lung Injury in Sickle Cell Disease. Am J Respir Crit Care Med. 2020;201(1):33-46. 
40. Annarapu G, Nolfi-Donegan D, Reynolds M, Wang Y, Shiva S. Mitochondrial reactive oxygen species scavenging attenuates thrombus formation in a murine model of sickle cell disease. $J$ Thromb Haemost. 2021.

41. Maynard DM, Heijnen HF, Horne MK, White JG, Gahl WA. Proteomic analysis of platelet alphagranules using mass spectrometry. J Thromb Haemost. 2007;5(9):1945-1955.

42. Whiteheart SW. Platelet granules: surprise packages. Blood. 2011;118(5):1190-1191.

43. Chatterjee $M$, Huang Z, Zhang $W$, et al. Distinct platelet packaging, release, and surface expression of proangiogenic and antiangiogenic factors on different platelet stimuli. Blood. 2011;117(14):3907-3911.

44. Golebiewska EM, Poole AW. Secrets of platelet exocytosis - what do we really know about platelet secretion mechanisms? Br J Haematol. 2013.

45. Jonnalagadda D, Izu LT, Whiteheart SW. Platelet secretion is kinetically heterogeneous in an agonist-responsive manner. Blood. 2012;120(26):5209-5216.

46. Prakash P, Kulkarni PP, Chauhan AK. Thrombospondin 1 requires von Willebrand factor to modulate arterial thrombosis in mice. Blood. 2015;125(2):399-406.

47. Kuijpers MJ, de Witt S, Nergiz-Unal R, et al. Supporting roles of platelet thrombospondin-1 and CD36 in thrombus formation on collagen. Arterioscler Thromb Vasc Biol. 2014;34(6):1187-1192.

48. Bonnefoy A, Daenens K, Feys HB, et al. Thrombospondin-1 controls vascular platelet recruitment and thrombus adherence in mice by protecting (sub)endothelial VWF from cleavage by ADAMTS13. Blood. 2006;107(3):955-964.

49. Lopez-Dee Z, Pidcock K, Gutierrez LS. Thrombospondin-1: multiple paths to inflammation. Mediators Inflamm. 2011;2011:296069.

50. Stein EV, Miller TW, Ivins-O'Keefe K, Kaur S, Roberts DD. Secreted Thrombospondin-1 Regulates Macrophage Interleukin-1beta Production and Activation through CD47. Sci Rep. 2016;6:19684.

51. Isenberg JS, Martin-Manso G, Maxhimer JB, Roberts DD. Regulation of nitric oxide signalling by thrombospondin 1: implications for anti-angiogenic therapies. Nat Rev Cancer. 2009;9(3):182-194.

52. Leung LL. Role of thrombospondin in platelet aggregation. J Clin Invest. 1984;74(5):1764-1772. 53. Bonnefoy A, Hantgan R, Legrand C, Frojmovic MM. A model of platelet aggregation involving multiple interactions of thrombospondin-1, fibrinogen, and GPIIbllla receptor. J Biol Chem. 2001;276(8):5605-5612.

54. Xing T, Wang Y, Ding WJ, et al. Thrombospondin-1 Production Regulates the Inflammatory Cytokine Secretion in THP-1 Cells Through NF-kappaB Signaling Pathway. Inflammation. 2017;40(5):1606-1621.

55. Ahamed J, Janczak CA, Wittkowski KM, Coller BS. In vitro and in vivo evidence that thrombospondin-1 (TSP-1) contributes to stirring- and shear-dependent activation of platelet-derived TGF-beta1. PLoS One. 2009;4(8):e6608.

56. Chen Y, Leask A, Abraham DJ, et al. Thrombospondin 1 is a key mediator of transforming growth factor beta-mediated cell contractility in systemic sclerosis via a mitogen-activated protein kinase kinase (MEK)/extracellular signal-regulated kinase (ERK)-dependent mechanism. Fibrogenesis Tissue Repair. 2011;4(1):9.

57. Liu Z, Morgan S, Ren J, et al. Thrombospondin-1 (TSP1) contributes to the development of vascular inflammation by regulating monocytic cell motility in mouse models of abdominal aortic aneurysm. Circ Res. 2015;117(2):129-141. 
58. Isenberg JS, Frazier WA, Roberts DD. Thrombospondin-1: a physiological regulator of nitric oxide signaling. Cell Mol Life Sci. 2008;65(5):728-742.

59. Isenberg JS, Wink DA, Roberts DD. Thrombospondin-1 antagonizes nitric oxide-stimulated vascular smooth muscle cell responses. Cardiovasc Res. 2006;71(4):785-793.

60. Novelli EM, Kato GJ, Ragni MV, et al. Plasma thrombospondin-1 is increased during acute sickle cell vaso-occlusive events and associated with acute chest syndrome, hydroxyurea therapy, and lower hemolytic rates. Am J Hematol. 2012;87(3):326-330.

61. Adegoke SA, Smith OS, Adeniyi AT, Adekile AD. Thrombospondin-1 and Vitamin D in Children With Sickle Cell Anemia. J Pediatr Hematol Oncol. 2019;41(8):e525-e529.

62. Gawaz M, Dickfeld T, Bogner C, Fateh-Moghadam S, Neumann FJ. Platelet function in septic multiple organ dysfunction syndrome. Intensive Care Med. 1997;23(4):379-385.

63. van der Wekken RJ, Kemperman $H$, Roest $M$, de Lange DW. Baseline thrombospondin-1 concentrations are not associated with mortality in septic patients: a single-center cohort study on the intensive care unit. Intensive Care Med Exp. 2017;5(1):7.

64. Novelli EM, Little-Ihrig L, Knupp HE, et al. Vascular TSP1-CD47 signaling promotes sickle cellassociated arterial vasculopathy and pulmonary hypertension in mice. Am J Physiol Lung Cell Mol Physiol. 2019;316(6):L1150-L1164.

65. McMaken S, Exline MC, Mehta $P$, et al. Thrombospondin-1 contributes to mortality in murine sepsis through effects on innate immunity. PLoS One. 2011;6(5):e19654.

66. Belcher JD, Chen C, Nguyen J, et al. Heme triggers TLR4 signaling leading to endothelial cell activation and vaso-occlusion in murine sickle cell disease. Blood. 2014;123(3):377-390.

67. Figueiredo RT, Fernandez PL, Mourao-Sa DS, et al. Characterization of heme as activator of Tolllike receptor 4. J Biol Chem. 2007;282(28):20221-20229.

68. Bijur GN, Jope RS. Rapid accumulation of Akt in mitochondria following phosphatidylinositol 3kinase activation. J Neurochem. 2003;87(6):1427-1435.

69. Li C, Li Y, He L, et al. PI3K/AKT signaling regulates bioenergetics in immortalized hepatocytes. Free Radic Biol Med. 2013;60:29-40.

70. Yu Y, Savage RE, Eathiraj S, et al. Targeting AKT1-E17K and the PI3K/AKT Pathway with an Allosteric AKT Inhibitor, ARQ 092. PLoS One. 2015;10(10):e0140479.

71. Janciauskiene S, Vijayan V, Immenschuh S. TLR4 Signaling by Heme and the Role of HemeBinding Blood Proteins. Front Immunol. 2020;11:1964.

72. Mense SM, Zhang L. Heme: a versatile signaling molecule controlling the activities of diverse regulators ranging from transcription factors to MAP kinases. Cell Res. 2006;16(8):681-692.

73. Nergiz-Unal R, Lamers MM, Van Kruchten R, et al. Signaling role of CD36 in platelet activation and thrombus formation on immobilized thrombospondin or oxidized low-density lipoprotein. J Thromb Haemost. 2011;9(9):1835-1846.

74. Rogers NM, Sharifi-Sanjani M, Csanyi G, Pagano PJ, Isenberg JS. Thrombospondin-1 and CD47 regulation of cardiac, pulmonary and vascular responses in health and disease. Matrix Biol. 2014;37:92101.

75. Kale A, Rogers NM, Ghimire K. Thrombospondin-1 CD47 Signalling: From Mechanisms to Medicine. Int J Mol Sci. 2021;22(8).

76. Larsen R, Gozzelino R, Jeney V, et al. A central role for free heme in the pathogenesis of severe sepsis. Sci Transl Med. 2010;2(51):51ra71. 
77. Kaiser R, Frantz C, Bals R, Wilkens H. The role of circulating thrombospondin-1 in patients with precapillary pulmonary hypertension. Respir Res. 2016;17(1):96.

78. Browne PV, Mosher DF, Steinberg MH, Hebbel RP. Disturbance of plasma and platelet thrombospondin levels in sickle cell disease. Am J Hematol. 1996;51(4):296-301.

79. Masselli E, Pozzi G, Vaccarezza M, et al. ROS in Platelet Biology: Functional Aspects and Methodological Insights. Int J Mol Sci. 2020;21(14).

80. Mendez D, Arauna D, Fuentes F, et al. Mitoquinone (MitoQ) Inhibits Platelet Activation Steps by Reducing ROS Levels. Int J Mol Sci. 2020;21(17).

81. Melchinger H, Jain K, Tyagi T, Hwa J. Role of Platelet Mitochondria: Life in a Nucleus-Free Zone. Front Cardiovasc Med. 2019;6:153. 
(A)

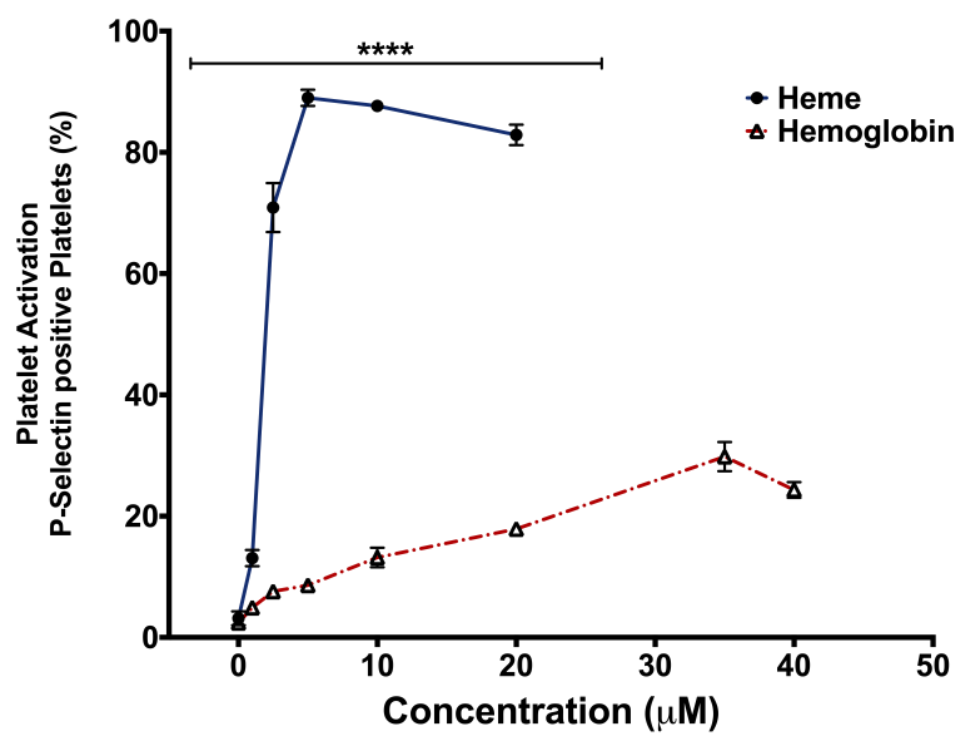

(C)

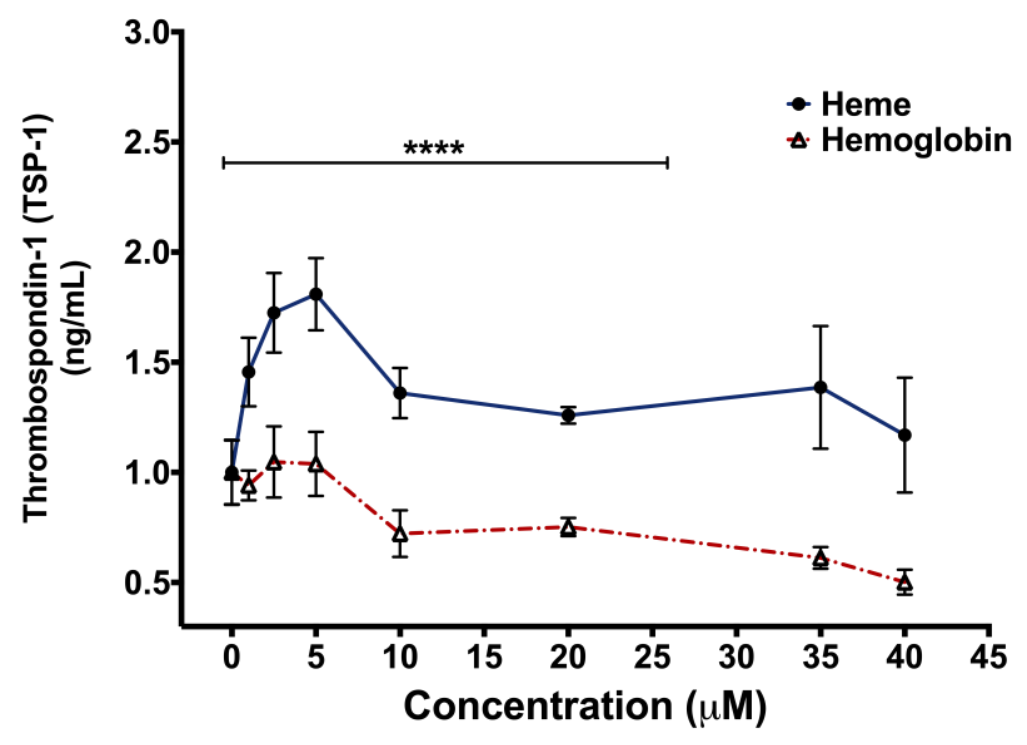

(B)

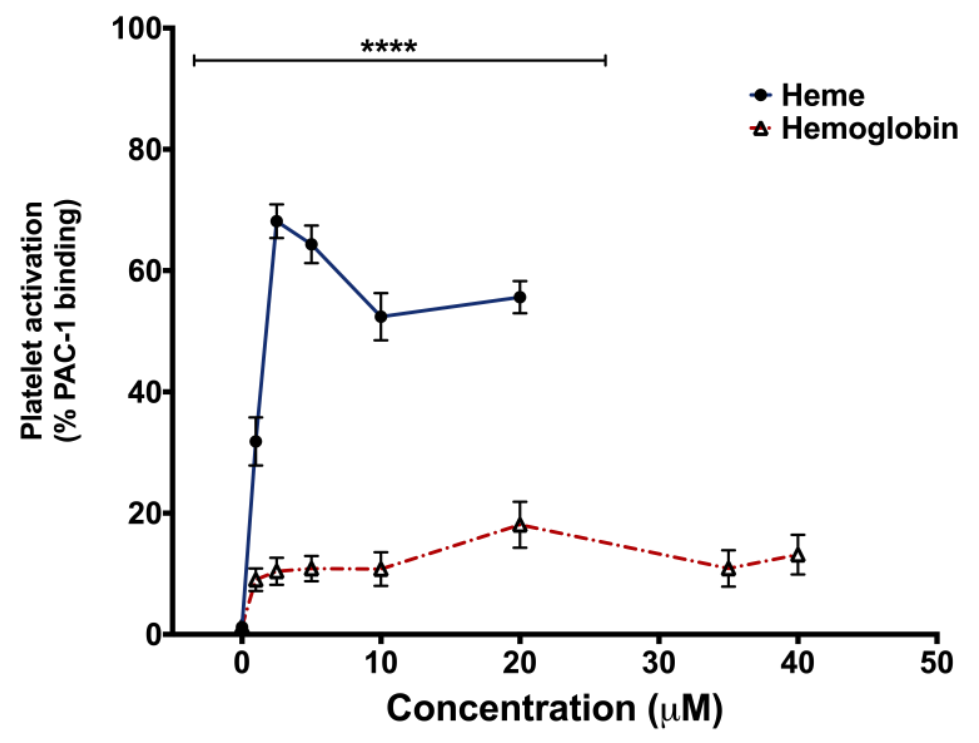

(D)

\section{Control}

Heme

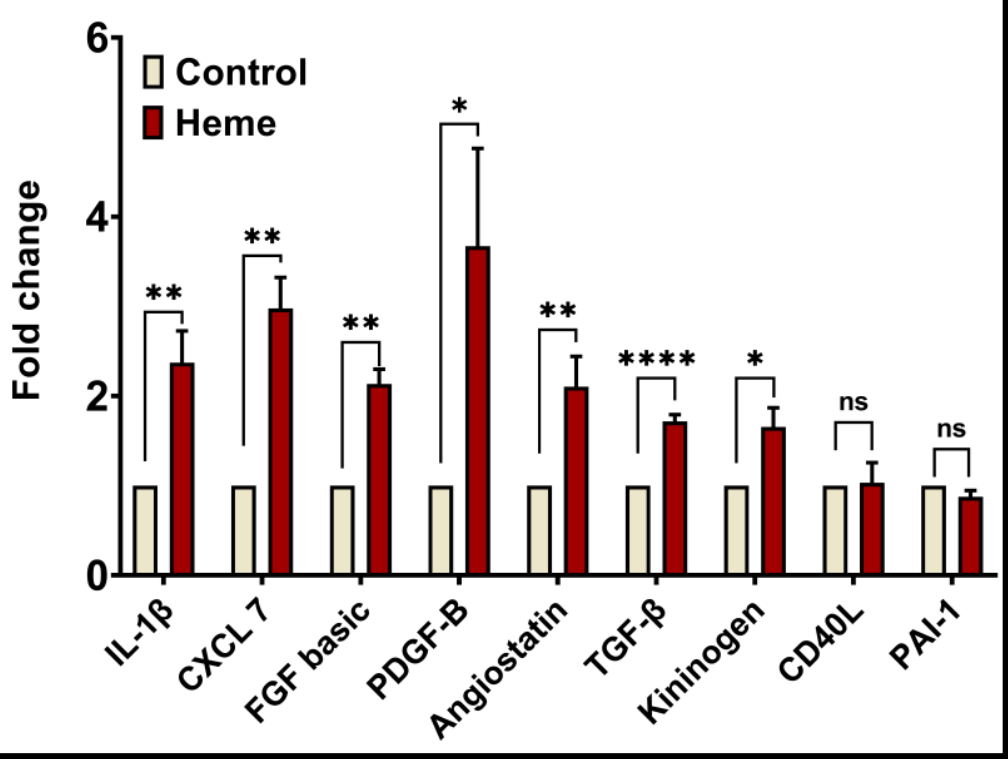

Figure 1. Heme is a more potent platelet agonist than hemoglobin . Platelet activation measured by (A) platelet surface P-selectin or (B) activated GPIIb/llla levels in heme (blue line) or methemoglobin (red line) treated platelets. (C) Thrombospondin-1 levels quantified in the releasate from heme (blue line) or methemoglobin (red line) treated platelets. (D) Dot blot with quantification of IL-1 $\beta$, CXCL7, FGF basic, PDGF-B, angiostatin, TGF $\beta$, kininogen, CD40L, PAI-1 levels in the releasate from heme $(2.5 \mu \mathrm{M})$ treated platelets. Data are represented as Mean $\pm \mathrm{SEM}$. ${ }^{* \star * *} p<0.0001$, ${ }^{* *} p<0.01,{ }^{*} p<0.05$, ns- not significant. $\mathrm{n}=3$. 


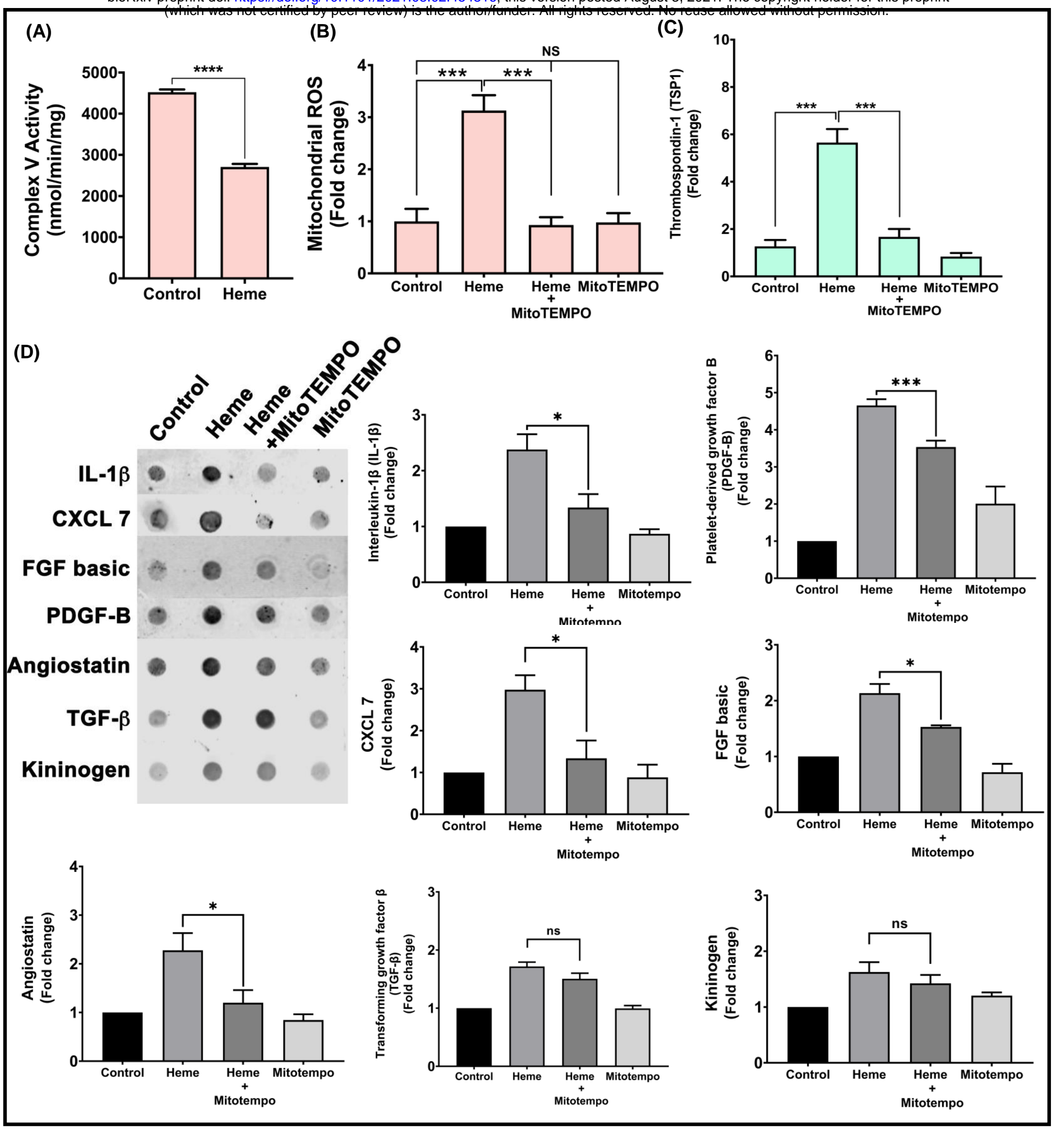

Figure 2. Heme inhibits platelet complex $\mathrm{V}$ activity and induces mtROS production that stimulates granule release. Platelets were treated with heme $(2.5 \mu \mathrm{M})$ in the presence or absence of MitoTEMPO $(10 \mu \mathrm{M})$ or with mitoTEMPO alone and (A) Platelet mitochondrial complex $V$ activity and (B) mtROS production were measured. (C) Thrombospondin-1 levels in the platelet releasate were measured. (D) Dot blot along with the quantification of levels of IL$1 \beta$, CXCL7, FGF basic, PDGF-B, angiostatin, TGF $\beta$ and kininogen in the platelet releasate. Data are Mean \pm SEM. ${ }^{* * *} p<0.0001,{ }^{* * *} p<0.001,{ }^{*} p<0.05$, ns- not significant. $n=4$ 
(which was not certified by peer review) is the author/funder. All rights reserved. No reuse allowed without permission.

(A)

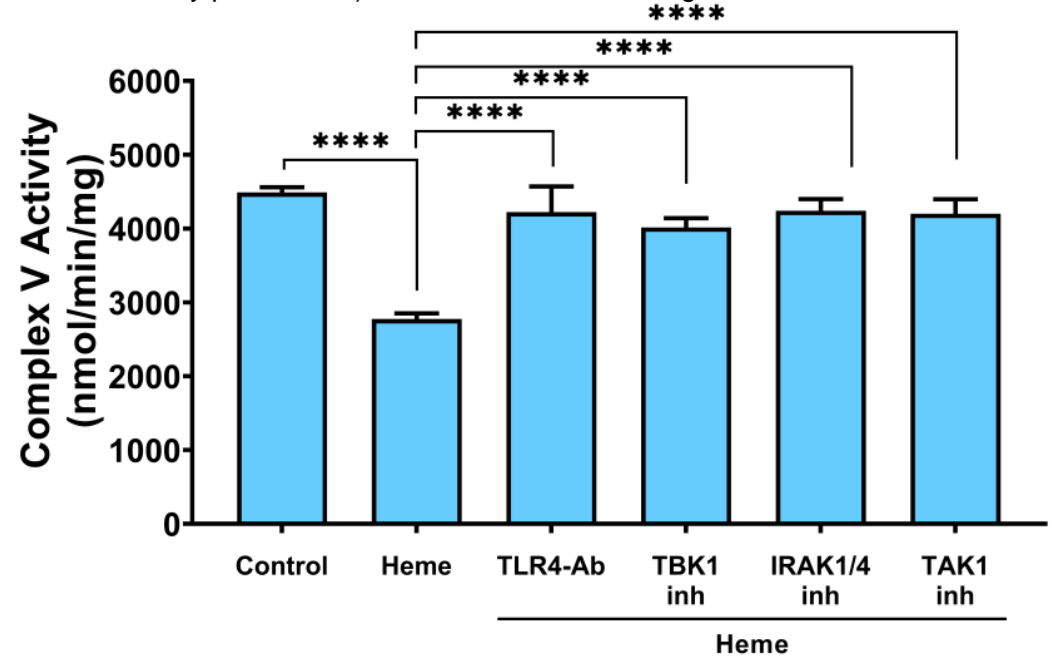

(B)

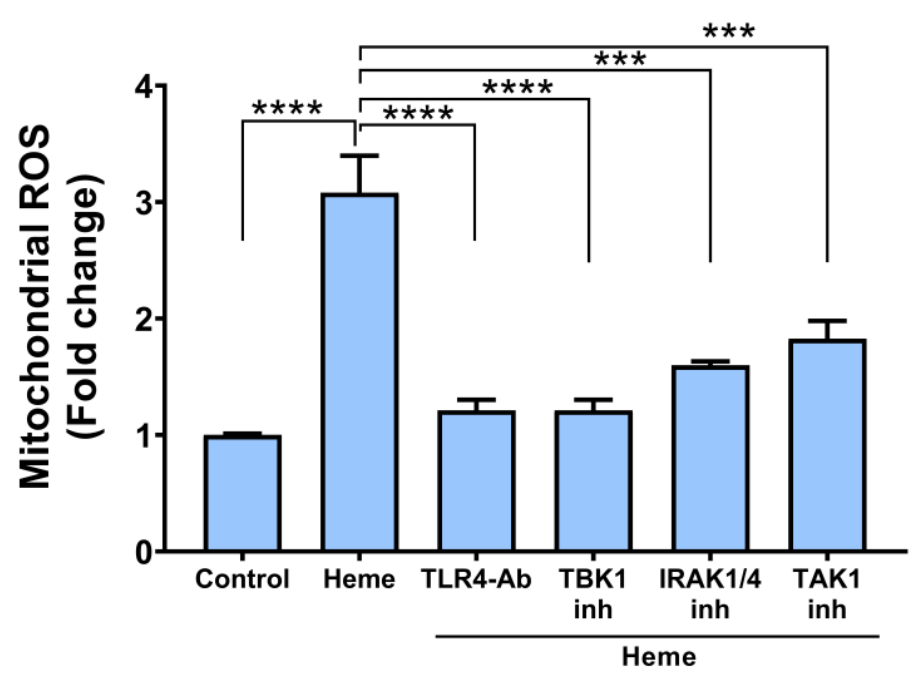

(C)

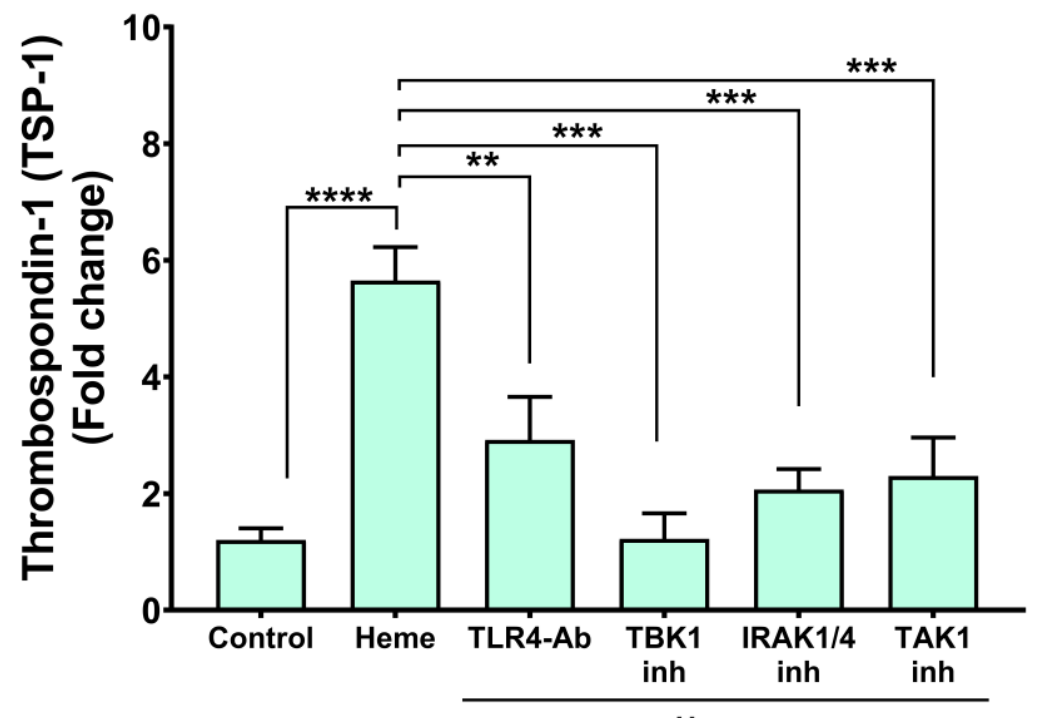

Heme

Figure 3. Heme inhibits platelet complex $\mathrm{V}$ activity to induces $\mathrm{mtROS}$ production and TSP-1 release via TLR4. (A) Platelet mitochondrial complex $\mathrm{V}$ activity, (B) platelet mtROS production, and $(\mathbf{C})$ thrombospondin-1 levels in the releasate were measured in heme-treated platelets in the presence or absence of TLR4 neutralizing antibody $(5 \mu \mathrm{g} / \mathrm{mL})$, pharmacological inhibitors of TBK1 (2 $\mu \mathrm{M}$ of BX795), IRAK1/4 (100 nM of N-[1-[2-(4-Morpholinyl)ethyl]-1Hbenzimidazol-2-yl]-3-nitrobenzamide), TAK1 ( $5 \mathrm{nM}$ of (5Z)-7-Oxozeaenol). Data are represented as Mean \pm SEM. ${ }^{* * \star *} p<0.0001,{ }^{* *} p<0.01,{ }^{* \star *} p<0.001 . \mathrm{n}=4$ 
bioRxiv preprint doi: https://doi,grg/10.1101/2021.08.02.454816; this version posted August 3, 2021. The copyright holder for this preprint (which was ngt certified byspeer review) is the author/funder. All rights reserved. No reuse allowed without permission.

(A)

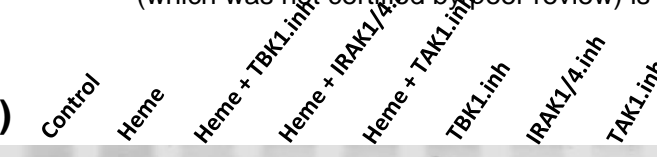

pAKT (S473)

Complex-V $\beta$-subunit

(B)
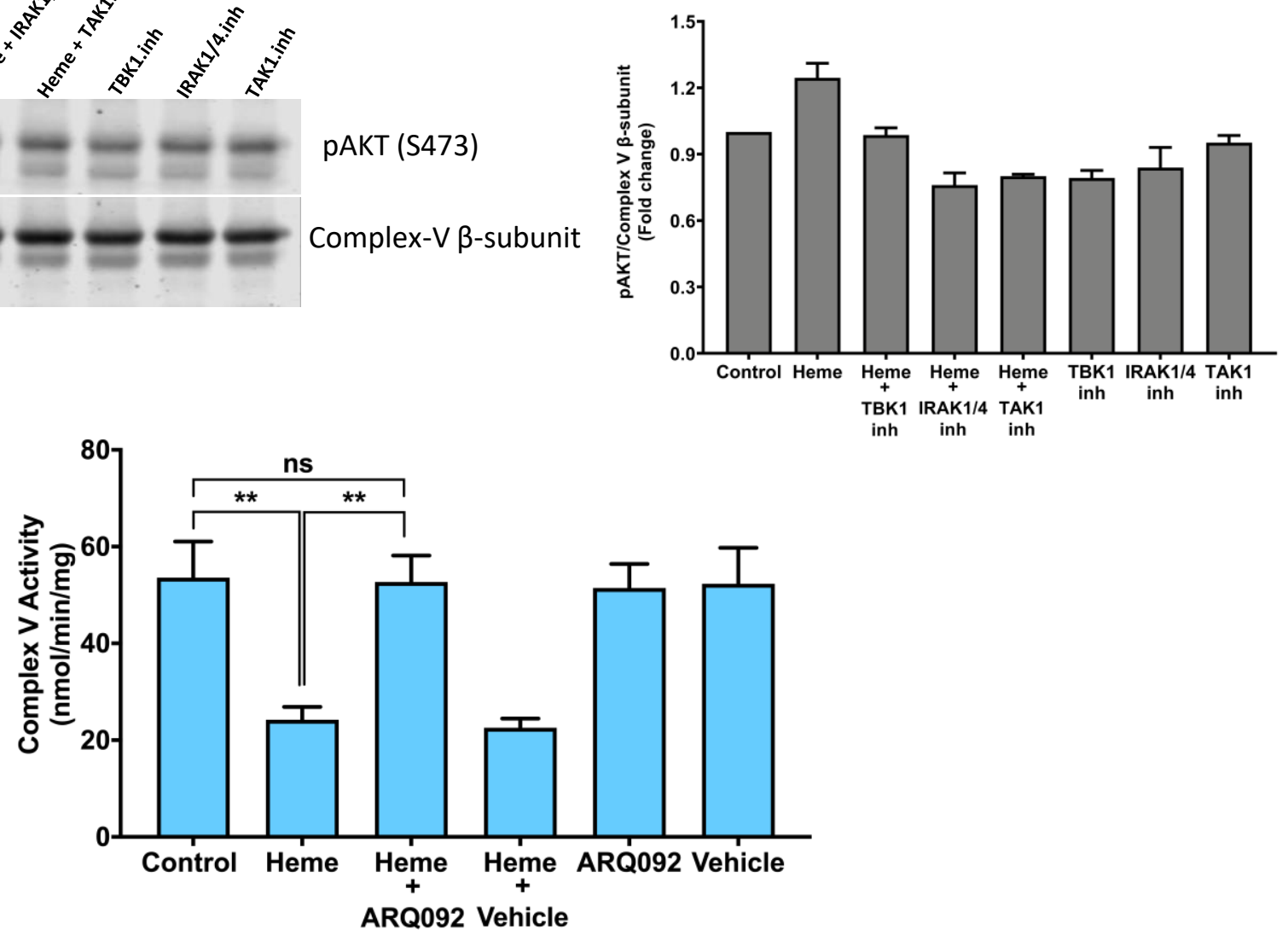

(C)

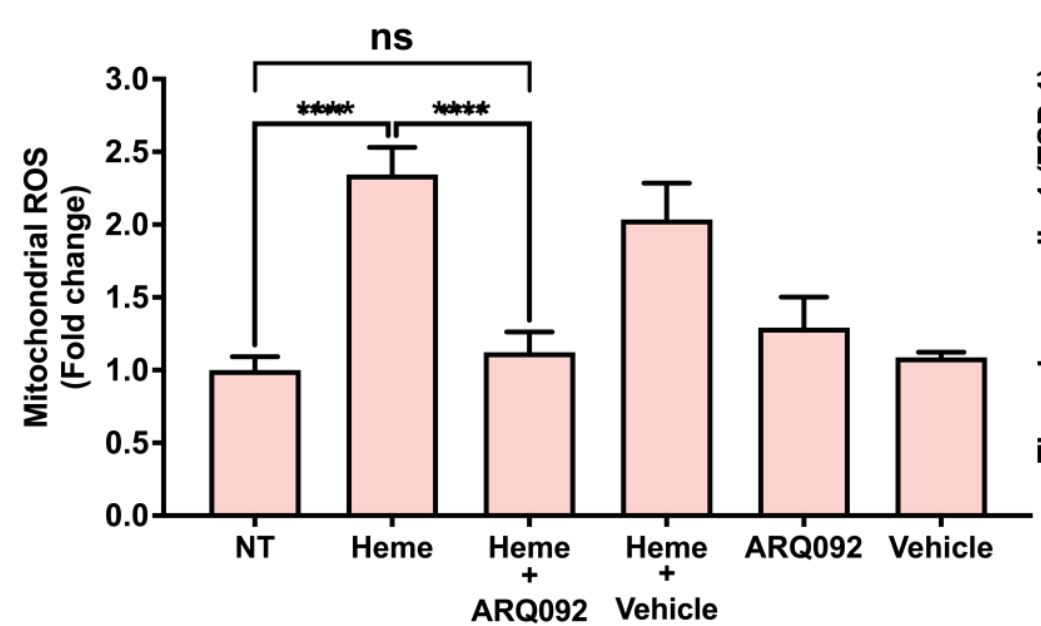

(D)

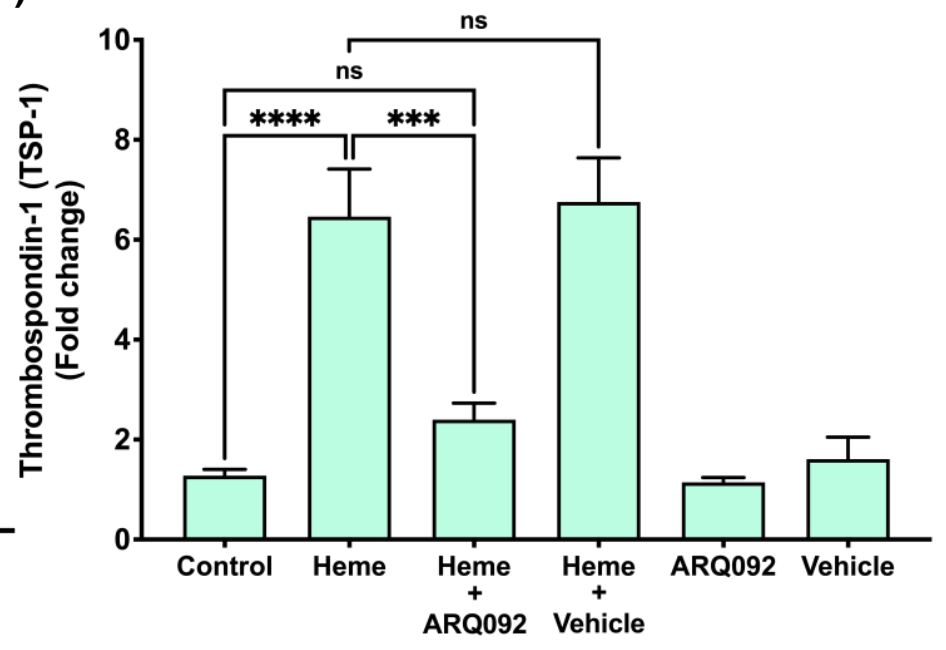

Figure 4. Heme-induced TLR4 signaling activates AKT to inhibit complex V activity in platelets.

(A) Platelets were treated with heme $(2.5 \mu \mathrm{M})$ in the presence or absence of TLR4 downstream signaling blockers (2 $\mu \mathrm{M}$ of BX795 (TBK1.inh), $100 \mathrm{nM}$ of $\mathrm{N}$-[1-[2-(4-Morpholinyl)ethyl]-1Hbenzimidazol-2-yl]-3-nitrobenzamide (IRAK1/4.inh) or $5 \mathrm{nM}$ of (5Z)-7-Oxozeaenol (TAK1.inh), and pAKT(S473) was measured in immunoprecipitated Complex-V beta subunit from platelet lysates. pAKT(S473) levels were normalized with complex $V$ beta subunit and plotted as fold change. (B) Platelet mitochondrial complex $V$ activity (C) mtROS production and (D) thrombospondin-1 release were measured in platelets pre-treated with or without ARQ092 (10 $\mu \mathrm{M})$ treated with heme $(2.5 \mu \mathrm{M})$. Data are represented as Mean \pm SEM. ${ }^{* * \star *} p<0.0001$, ${ }^{* * *} p<0.001,{ }^{* *} p<0.01$, ns - not significant. $n=4$. 
(A)

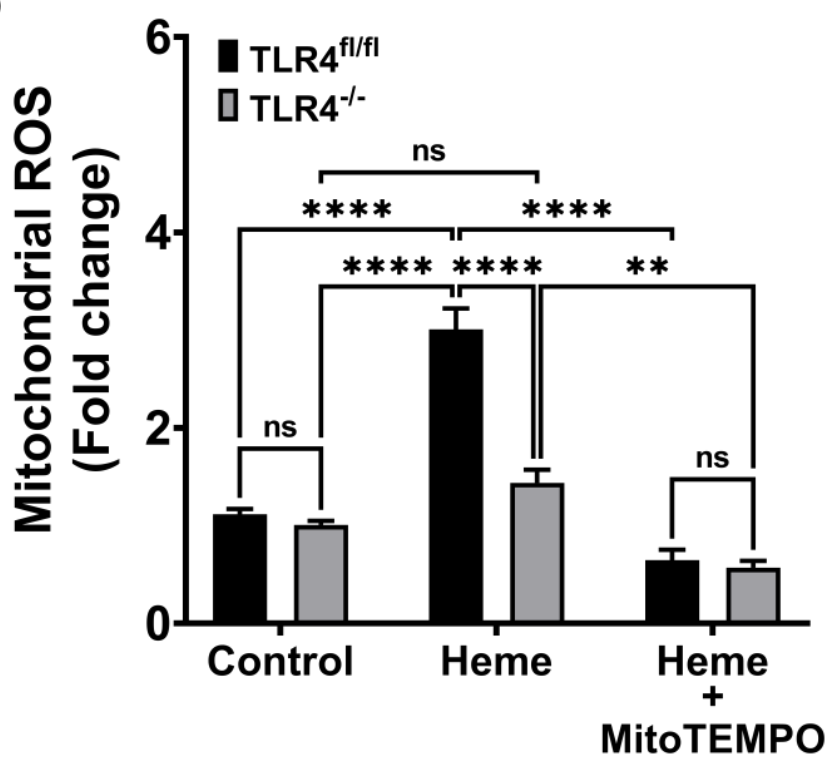

(C)

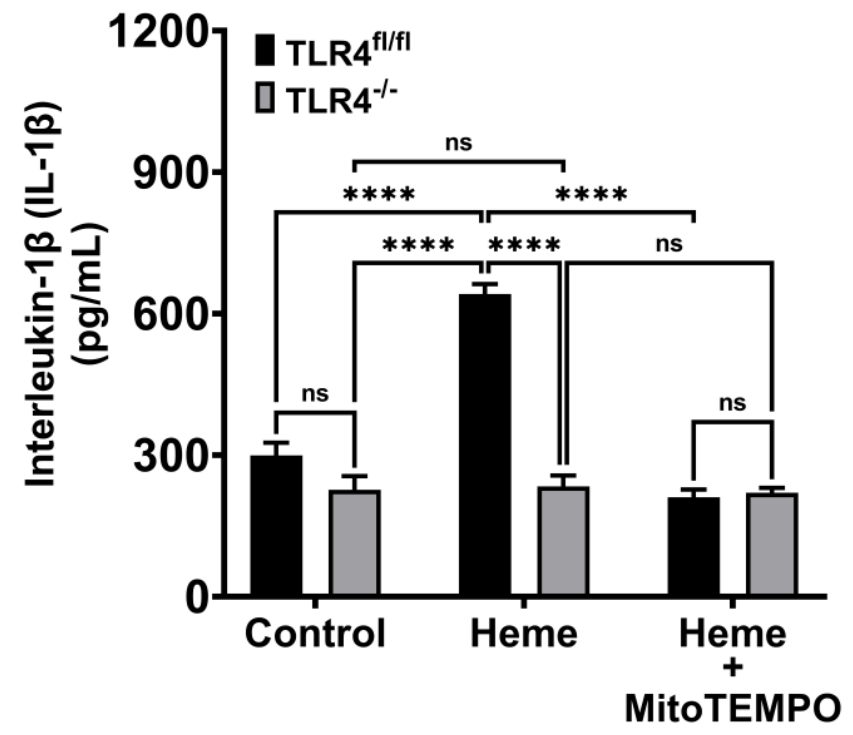

(B)

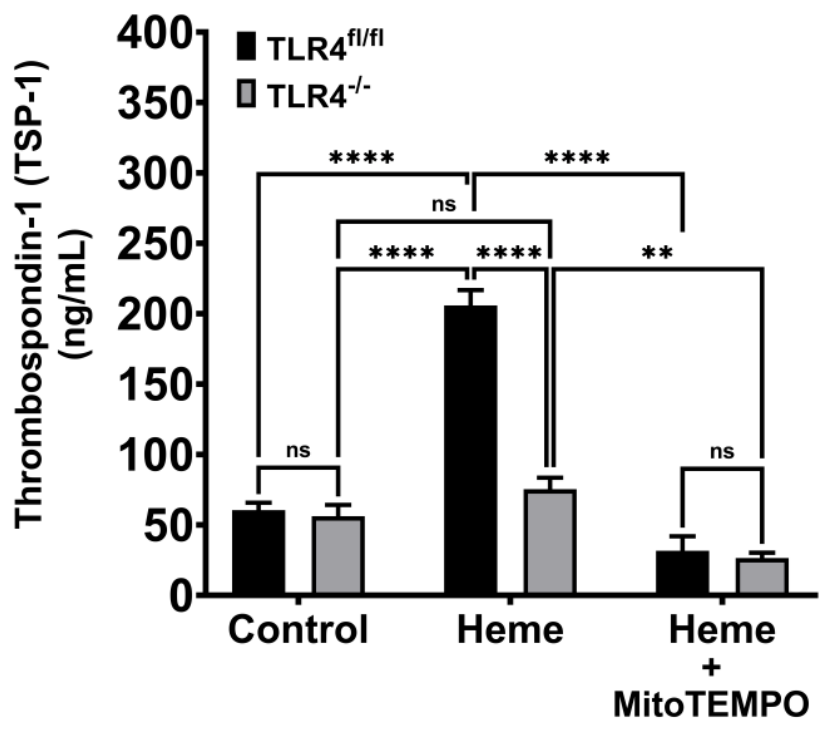

(D)

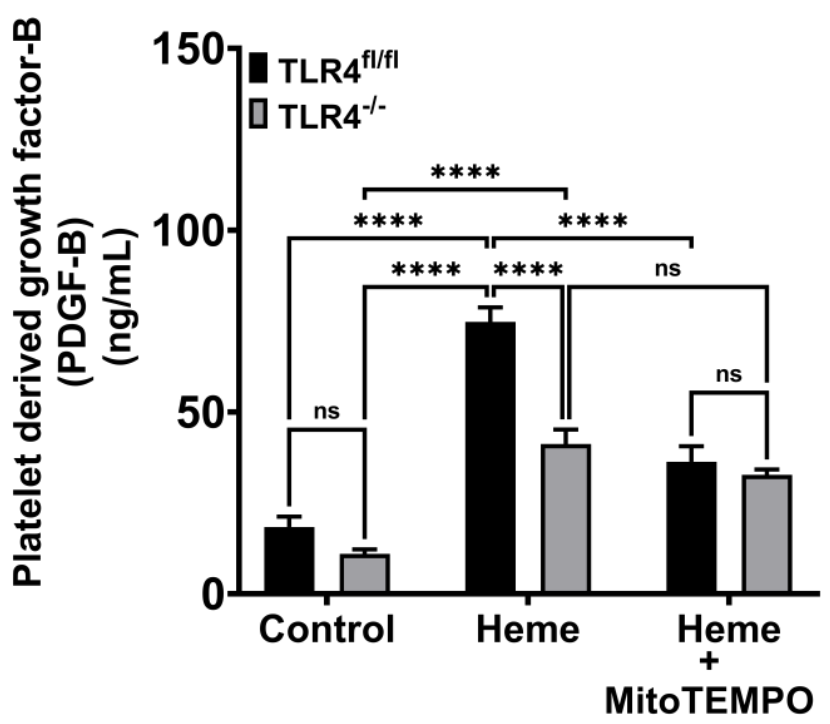

Figure 5. Heme infused TLR4 ${ }^{-/}$mice show attenuated mtROS production and heme induced granule release in platelets. TLR4 ${ }^{-/}$mice and TLR4 $4^{\mathrm{fl} / f l}$ mice (control mice) were pretreated with MitoTEMPO $(300 \mu \mathrm{M})$ and injected (i.v.) with heme $(110 \mathrm{mg} / \mathrm{kg})$. (A) Platelets mtROS was measured and plasma levels of (B) Thrombospondin-1, (C) Interleukin-1 $\beta$ and (D) Platelet derived growth factor- $B$ were measured. Data are represented as Mean \pm SEM. ${ }^{* * *} p<0.0001,{ }^{* *} p<0.001$, ns- not significant. $\mathrm{n}=5$ mice per group in control and heme treated groups; $\mathrm{n}=3$ to 4 mice in MitoTEMPO treated groups. 